\title{
One Design about Educational Game Based on Big Data on Campus
}

\author{
Peng Zhang \\ Suzhou Industrial Park Institute of Services Outsourcing, Suzhou, China \\ zhangp@siso.edu.cn
}

Keywords: Big data; Cloud computing; Game

\begin{abstract}
Under the background of the rapid development of information construction in Colleges and universities, this paper puts forward a design about educational network game. The design based on the analysis of the big data on campus, according to the different characteristics of students, provides a function which can enhance memory. At the same time, the design can be combined with the completed video, animation, homework and other teaching resources. This design integrates traditional resources into the game world.
\end{abstract}

\section{Introduction}

With the development of time, the traditional teaching mode has been difficult to attract students' interest in learning, and the teaching method based on the network game is worth studying. Although there are many educational games have been developed and applied to teaching, but a lot of games' designs do not fully suitable for modern education. Some educational games are just fun games, they lack educational features. On the other hand, although some games ha educational features, they are less playable.

Excellent educational games should be able to combine existing teaching resources, and suitable for a variety of teaching activities. In addition, the analysis of big data on campus, will dig out useful information into online games. Designs about educational games are worth discussing and studying.

\section{The Relationship between Game Types and Teaching Activities.}

In recent years, the popular online games are mainly two categories: web games and multiplayer online games. A web game generally provides only a single experience. However, in multiplayer online games, players can communicate with each other. Multiplayer online games can also be divided into small-flow games and MMRPG games.

Small-flow games require less data. Most of them are chess games. In these games, players will be divided into several groups. In each group, the players play in a certain order.

MMRPG game also known as the online role-playing game. These games require a large amount of data transmission. In these games, thousands of players come together and play different roles.

The corresponding relationship between games and teaching activities is shown in Fig.1.

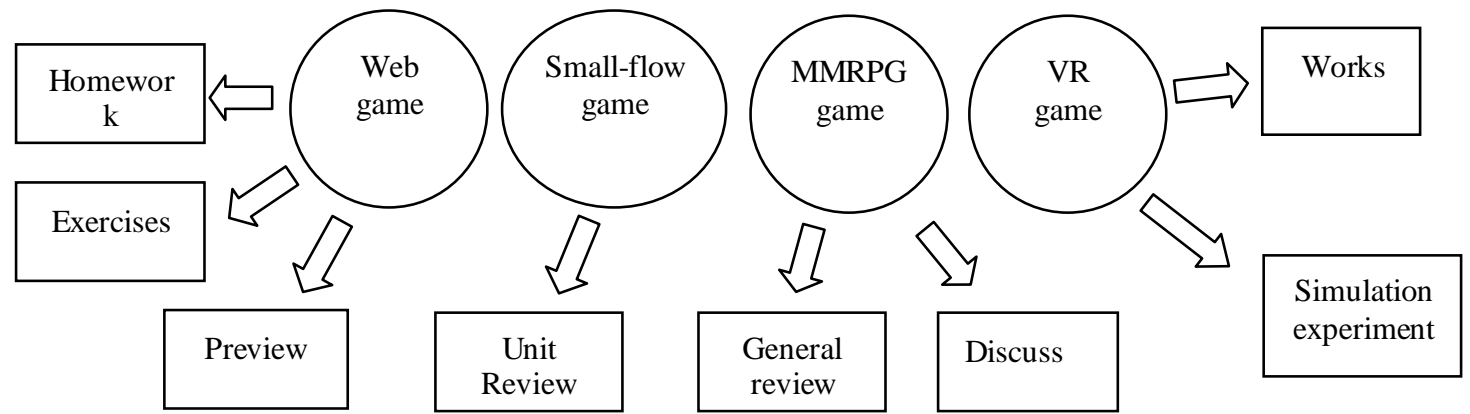

Figure 1. The corresponding relationship between games and teaching activities

Web games can be played at any time; they fit into online homework, preview and other teaching activities. Small-flow game is suitable for teaching activities with moderate knowledge, such as unit 
testing, unit review. MMRPG game is suitable for integration into the general review, discussion, and other teaching activities to provide students with a virtual world of mutual exchange.

In addition, virtual reality (VR) technology has developed rapidly in recent years. Only in the first quarter of 2016, global investment in VR has more than 1 billion $\$ 700$ million U.S. (data from "China's virtual reality (VR) industry development prospects and investment strategy planning analysis report forward-looking"). Virtual reality technology uses computer graphics system and peripheral control equipment to display three-dimensional "real" environment. Using this technology, we can move the laboratory into a virtual game world, so that students can experience the real experiment in the dormitory.

\section{The Combination of Game Content and Existing Teaching Resources.}

Many colleges and universities have completed the construction of teaching resources, so education online games should be able to integrate with the existing teaching resources. The game information database can be integrated with the existing teaching resources through a unified access interface. This forms a complete service system, as shown in Fig. 2.

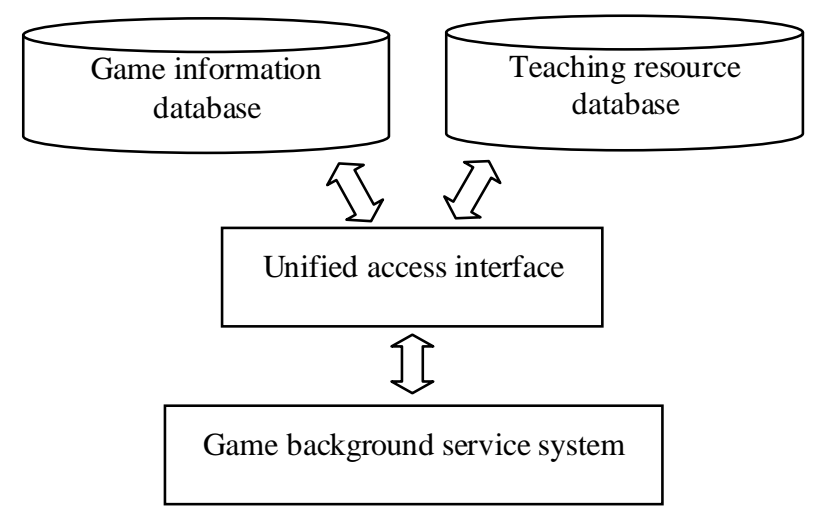

Figure 2. Unified access interface

The background of the game service system, should provide a variety of editing tools to facilitate teachers to quickly edit the traditional teaching resources into the game content. For example, through the editing tool, teachers can edit the corresponding content of the page game, or edit the teaching video in the exhibition hall in the game, or adjust the content of VR virtual experiment. At the same time, teachers can adjust the content of the game according to the progress of the teaching or the feedback of the students.

\section{An Enhanced Memory System based on Big Data.}

In recent years, the information construction on campus is very rapid. Many colleges and universities have built their own teaching management platform, experimental management platform, and card management system, etc. In the long term, these systems store large amounts of data. Through the analysis of these data, we can understand the students' work and rest time, learning interest, personality characteristics, memory characteristics and other information.

Educational game system should make full use of big data to form the function system of strengthening memory. According to the different characteristics of the students, the game system can automatically adjust the time and frequency of preview, review, and small measurement. For example, if the system found that some students have poor memory, the game system needs to improve the frequency of reviews and tests for these students. Another example, according to different students' daily habits, the game system automatically adjust the review and test time, in order to achieve the best learning results. Game system can also be adjusted according to the interests of students. For example, the game system as far as possible to provide a relaxed and enjoyable games for girls, and try to give boys a little nervous stimulation game. 


\section{Summary}

Educational games based on big data and teaching resources can make students learn and communicate happily. The students finished the study of knowledge unconsciously. This is a new teaching mode.

\section{Acknowledgements}

This research was financially supported by the Jiangsu Province Department of Education Reform Project (No. 2015JSJG396) and the Jiangsu Province Modern Educational Technology Project(No. 2016-R-47504).

\section{References}

[1] Gwo-Jen Hwang, Han-Yu Sung, Chun-Ming Hung, Iwen Huang, Chin-Chung Tsai. Development of a personalized educational computer game based on students' learning styles[J]. Educational Technology Research and Development . 2012 (4)

[2] Sasha Barab, Patrick Pettyjohn, Melissa Gresalfi, Charlene Volk, Maria Solomou. Game-based curriculum and transformational play: Designing to meaningfully positioning person, content, and context[J]. Computers \& Education . 2011 (1)

[3] Thomas M. Connolly, Mark Stansfield, Thomas Hainey. An alternate reality game for language learning: ARGuing for multilingual motivation[J]. Computers \& Education . 2011 (1)

[4] Marsh. H.W, Peart , N.D. Copetitive and cooperative physical fitness training forgirls: Effect 011 physical fitness and multidimensional self-concepts. Journal of sportsand Exercise Psychology . 2009

[5] Glenda A. Gunter, Robert F. Kenny, Erik H. Vick. Taking educational games seriously: using the RETAIN model to design endogenous fantasy into standalone educational games[J]. Educational Technology Research and Development . 2008 (5) 